\title{
Relation of fruit development to the incidence of Blossom-end Rot of tomatoes
}

\section{J. WESTERHOUT}

University of Ghana, Nigeria. At present: Département des Recherches, Plantations Lever au Congo (Research Department of Lever plantations in Congo), Yaligimba, Congo

\section{Summary}

In Ghana experiments with tomatoes were conducted in a greenhouse to investigate factors responsible for the incidence of blossom-end rot under tropical conditions.

The incidence, mostly being confined to the fruits of the first cluster, was strongly influenced by the vigour of the plant. In vigorously growing plants the incipient stages of blossom-end rot occurred from 7 to 10 days after anthesis during a period that the plants seem to be very sensitive to calcium deficiency. Plants with less growth vigour produced only normal fruits.

Calcium deficiency in the plant and the rate of fruit growth, both factors closely related to the vigour of the plant, seemed to be responsible for the prevalence and severity of the disorder.

An increase or decrease of the rate of fruit growth by changing the assimilating leaf area affected the incidence of blossom-end rot similarly.

Calcium deficiency in the plant has not always to produce blossom-end rot of the fruit. It was found that calcium deficiency in the fruit only appeared when the rate of fruit growth exceeded a certain limit.

Slowly developing fruits were not affected by the disorder even when severe calcium deficiency symptoms in the plant were visible.

\section{Introduction}

In Ghana a great demand for tomatoes exists; these are nearly all produced locally. Near Accra where many vegetables are cultivated, tomato growing is important. Yields are, however, poor and do not exceed $350 \mathrm{~g}$ of fruits per plant. The low yields can be partly attributed to improper management without use of a fertilizer. The main factor seems to be a climate unsuitable for tomato production. The average day temperature is $86^{\circ} \mathrm{F}$ and the average night temperature $78^{\circ} \mathrm{F}$; the relative humidity ranges from $60 \%$ at noon to $90 \%$ at night.

All these factors adversely affect setting and development of tomato fruit and favour the incidence of diseases. Investigations at the University Agricultural Station Nungua near Accra proved nevertheless that increases in yield up to $50 \%$ are possible by using other than local varieties and by giving proper attention to the crop. At the same time, however, the incidence of blossom-end rot not present in the fields of local producers appeared. The disease caused $\pm 25 \%$ rotting of the fruits before they were fully ripe.

From this result it seemed important to investigate the problem of blossom-end rot

Received for publication 13th April, 1962.

Neth. J. agric. Sci., Vol. 10 (1962) No. 3 (August) 
on which a great deal of research has been done in temperate and subtropical regions, but not in the tropics. Experiments based on the results obtained in other countries where the disorder is common, were made during 1960-1962 under semi-controlled conditions in a greenhouse at the University of Ghana, Legon, near Accra.

The purpose of this study was to investigate which of many causal factors suggested in the literature, or any other factors, are responsible for the incidence of blossomend rot under tropical conditions.

\section{Review of literature}

Symptoms. Blossom-end rot becomes apparent as a green water-soaked area under the fruit wall on the stylar end of the fruit. Small brown flecks may develop within the affected area. Within a week the lesion attains its full size and has a brownish colour. At maturity of the fruit the affected area results in a blackened, dry, sunken leathery spot. The periphery of the lesion is surrounded by an irregular yellowish area (GuSTAFson, 1937; SPURR, 1959).

Causes. Blossom-end rot is a physiological disorder; its causes are not known with certainty. Unfavourable moisture conditions and calcium deficiency are supposed to be the most important factors in its causation.

The restriction of water availability to the plant and to the fruit can be the result of low soil moisture (STOUT, 1934; GroENEWEGEN, 1957), a high soil conductivity (RobBINS, 1937, HÅR, 1957), a poorly developed root-system (GROENEWEGEN, 1957) or a lack of equilibrium between water intake and evaporation (RIEUF, 1954).

It follows that any factor which either seriously restricts the rate of absorption or greatly increases the rate of transpiration of water by the plant increases the probability of the incidence.

Histological studies of affected tomato fruits (SPURR, 1959) indicated calcium deficiency in the fruit as the basic cause of blossom-end rot. Geraldson (1957) found a correlation between the prevalence and severity of blossom-end rot with the percentages of calcium in the soil solution. Tomato plants grown under calcium deficiency in nutrient cultures produced the disorder (McIlrath, 1959).

Other factors reported to increase the incidence of blossom-end rot are vigorous growth of the plant (LEOPOLD and GUERNSEY, 1953), single-stem pruning (BAIN, 1954), poor fruit setting (GroenEwegen, 1957) and high temperature (HulEa, 1958). Geraldson $(1955,1957)$ believed that many factors reported to be causal agents of blossomend rot produce their effect by depressing the availability of calcium to the fruit.

\section{Experimental}

Based on the findings of authors mentioned above, a series of observational experiments were conducted during 1959-1961 to obtain information which factors under our conditions seem to be responsible for the occurrence of blossom-end rot. These experiments were followed by a "replicated" experiment in which those treatments were selected from the results obtained in the observational experiments that were expected to be of use in analysing the incidence of the disorder.

Location and conditions. All experiments were conducted at the Faculty of Agriculture of the University of Ghana, Legon, near Accra in a greenhouse. The greenhouse can be compared with an ordinary glasshouse except that mosquito netting replaces glass in the side walls; the roof is of glass. 
The light intensity was observed to be reduced to about $70 \%$; temperature and relative humidity were practically the same as in the open. The greenhouse was fully protected against rain, making it possible to control the water supply to the plant.

Variety. The variety Moneymaker, obtained from the Horticultural Station at Naaldwyk, Holland, was used.

Soil. Medium light soil (Agawtaw series) from the University Station Nungua with a water-storage capacity of $15 \%$ was selected because field experiments with potatoes have been conducted on this soil type. Soil volume: 4 gallon.

Cultivation. Three-weeks old seedlings were transplanted in 4 gallon containers filled with Agawtaw topsoil.

At planting $3 \mathrm{~g}$ Potash chilean nitrate (P.C.N.) and $10 \mathrm{~g}$ triple superphosphate (T.S.) were applied to each pot followed by a top-dressing of $1 \frac{1 / 2}{g}$ of P.C.N. after setting of the successive clusters. The plants were pruned to single stem and staked. Only four clusters were allowed to develop.

Water supply. Until anthesis of the first flower the water supply varied from three to ten litres per plant depending on the water regimes used. After anthesis all plants received adequate water by keeping the soil at about $75 \%$ of its field capacity.

Spraying. Weekly spraying with Zineb $(300 \mathrm{mg} / 1)$ to control diseases. If not otherwise stated the above mentioned basic treatments were used.

\subsection{Observational experiments}

The object of the observational experiments was to obtain indications which factors might be responsible for the incidence of blossom-end rot under our tropical conditions. The following experiments were conducted during 1960-1961.

a. Variety trial in which the variety Moneymaker was compared with Ailsa Craig, Glory and Potentate to investigate the varietal susceptibility to the disorder.

b. Soil-moisture trials to investigate the effect of water stress.

b.1. The effect of two different water regimes on the incidence was observed. In the high soil-moisture treatment 101 of water were supplied during the first three weeks after transplanting, this quantity being adequate for vigorous growth until anthesis of the first flower. In the low soil-moisture treatment only 31 were supplied during the same period to reduce the growth of the plant. This quantity prevented the plants just from wilting. After anthesis ample water was supplied to keep the soil at $75 \%$ of its field capacity.

b.2. Plants were allowed to extend their root system in beakers containing 51 of water through which air was blown.

b.3. After anthesis of the first flower plants were forced to wilt for short periods during two weeks.

b.4. Soil was kept at field capacity during the development of the first cluster.

c. Soil-type trial to investigate the effect of a heavy clay soil (Akuse series) rich in calcium; a light red soil (Nyagimba series) with excellent drainage properties and the standard medium-light Nungua soil (Agawtaw series) on the incidence of blossom-end rot.

d. Calcium trial; calcium chloride ( $5 \mathrm{~g}$ per plant) was applied just before flowering to observe the effect of the calcium content of the soil solution on the incidence.

e. Pot-size trial; 6 gallon containers were compared with the standard 4 gallon containers to investigate the effect of different soil volumes on the disorder. 
f. Pruning trial; tomato plants were allowed to produce two vigorous shoots in addition to the main stem. The effect of this pruning system was compared with the standard single-stem pruning system.

g. Nitrogen trial; to obtain information about the effect of no nitrogen, $3 \mathrm{~g}$ P.C.N. $(15,5 \% \mathrm{~N})$ at planting, and $1 \frac{1 / 2}{\mathrm{~g}}$ of P.C.N. at planting and $1 \frac{1}{2}$ g P.C.N. at flowering.

\section{RESULTS}

Symptoms of blossom-end rot. Our observations did not differ from the discription of the disorder given by GUSTAFSON (1937) and SPURR (1959) except that separate small brown flecks appeared before the green water-soaked area developed, and that on slightly affected fruits the small flecks $(1 \mathrm{~mm})$ did not fuse together to one large lesion, while the water-soaked area was absent even during the later stages of the development of the fruit. The first visible symptoms of the disease appeared at night.

Incidence of blossom-end rot. In the more vigorously growing varieties Ailsa Craig and Glory the prevalence and severity of the disorder were much greater than in the less vigorously growing varieties Moneymaker and Potentate (a). No significant difference in incidence of blossomend rot was produced by using different soil types (c) and different pot sizes (e).

The most remarkable effect on the incidence was obtained by supplying various soil-moisture levels. A low soil moisture never produced the disorder, while fruits of plants grown under high water regime were frequently affected (b.1.). Root extension in free water through which air was blown (b.2.) and abundant watering after fruit setting (b.4.) could not prevent the disease or reduce the incidence. Wilting of plants (b.3.) increased the number of affected fruits and the severity of the disorder under all circumstances.

A higher calcium level in the soil solution (d) did not result in a reduction of blossom-end rot. Blossom-end rot was reduced by adopting the multiple-stem system (f). Nitrogen applications (g) had only a limited effect on the occurrence.

\subsection{The "replicated" experiment}

The results of the observational experiments indicated growth vigour as one of the most important factors affecting the incidence of blossom-end rot. Apart from the variety effect the development of the plant was greatly influenced by the water regimes and to a less extent by nitrogen fertilizer. Therefore the treatments soilmoisture levels and nitrogen-fertilizer rates were selected for the "replicated" experiment (TABLE 1).

TABLE 1. Treatments of the "replicated" experiment

\begin{tabular}{ccccc}
\hline Treatment & Soil moisture & Nitrogen & Potash & Code \\
1 & high level & $3 \mathrm{~g} \mathrm{P.C.N.}$ & from P.C.N. & $3 \mathrm{H}$ \\
2 & low level & $3 \mathrm{~g} \mathrm{P.C.N.}$ & from P.C.N. & $3 \mathrm{~L}$ \\
3 & high level & nil & $1 \mathrm{~g} \mathrm{~K} \mathrm{SO}_{4}$ & $\mathrm{H}$ \\
4 & low level & nil & $1 \mathrm{~g} \mathrm{~K} \mathrm{SO}_{4}$ & $\mathrm{~L}$ \\
\hline
\end{tabular}

$1 \mathrm{~g}$ sulphate of potash contains a quantity of $\mathrm{K}_{2} \mathrm{O}$ equivalent to that of $3 \mathrm{~g}$ P.C.N.

There were four successive plantings at monthly intervals (October, November, December 1961 and January 1962). Each planting consisted of 24 plants; the main treatments were replicated six times.

The variety Moneymaker was grown in 4 gallon containers filled with Agawtaw medium-light soil. Apart from the fertilizer treatments, $10 \mathrm{~g}$ T.S. were applied at planting and top-dressings of $1 \frac{1}{2}$ g P.C.N. after setting of the successive clusters. 
In the high soil-moisture level treatments 101 of water were supplied during the first three weeks, in the low soil-moisture treatments 31 during the same period. The following additional treatments - only three replicates due to shortage of space - were introduced in the December and January plantings as a result of information obtained in the earlier plantings for the purpose of reducing or increasing fruit growth or reducing transpiration in the $3 \mathbf{H}$-treatments :

Removal of terminal bud after appearance of the second inflorescence;

Removal of the first inflorescence;

Removal of six bottom leaves at appearance of the first inflorescence;

Provision of shade after anthesis of the first flower;

Wilting after anthesis of the first flower;

Multiple-stem system.

The basic treatments were the same as for the "standard" 3H-treatment.

Observations and measurements. The height of plants showing correlation with the leaf-area production were measured during six weeks after transplanting at weekly intervals to obtain information about the vigour of the plant.

Special attention was given to the number of leaves produced at appearance of the first inflorescence to evaluate the effect of their leaf area on the incidence of blossom-end rot. First signs of calcium deficiency in the terminal bud as shown in colour photographs by WALLACE (1951), were recorded.

To obtain detailed information about the inception of blossom-end rot relative to the growth and age of the fruit, all open flowers of the first inflorescence and some of the second inflorescence were tagged with dated labels.

In order to analyse the growth rate of the fruit from 4 days after anthesis the diameter of each fruit was measured during 12 successive days when the inception of blossom-end rot was expected to appear. During 5 days of the susceptible period fruit measurements were taken twice a day to obtain information about possible differences in growth during day and night time.

At harvest the diameter and height of the tagged fruits were measured and also the diameter of the blossom-end rot lesion of affected fruits. The ratio diameter of lesion to diameter of fruit (code: L/F) closely indicated the severity of the disorder.

All fruits of the first cluster were counted and weighed, and classified as follows:

1. Healthy fruits;

code: $G$

2. Fruits showing only small flecks, no lesion; code: $\mathbf{S}$

3. Ratio L/F less than $25 \%$; code: $-25 \%$

4. Ratio L/F $26 \%-50 \%$;

5. Ratio $\mathrm{L} / \mathrm{F}$ more than $50 \%$;

code: $+25 \%$

code: $+50 \%$

The percentage of affected fruits was calculated.

\section{RESULTS}

Plant growth. The rate of plant growth and the production of leaf area were greatly influenced by the water regimes used. The number of leaves produced below the first inflorescence (table 2) did not vary for the high and low soil-moisture treatments but showed differences for the time of planting. The more leaves were produced the greater the percentage of affected fruits.

Calcium deficiency symptoms (WALLACE, 1951) appeared in the terminal buds of nearly all plants 6-15 days after anthesis of the first flower, dependent on the vigour of the plant. Mostly 


\section{J. WESTERHOUT}

TABle 2. Prevalence and severity of blossom-end rot on the first cluster for different plantings

\begin{tabular}{|c|c|c|c|c|c|c|c|c|c|c|}
\hline \multirow{2}{*}{$\begin{array}{l}\text { Time } \\
\text { of plant- } \\
\text { ing }\end{array}$} & \multirow{2}{*}{$\begin{array}{l}\text { Treat- } \\
\text { ment }\end{array}$} & \multicolumn{2}{|c|}{ First cluster } & \multirow{2}{*}{$\begin{array}{c}\text { Normal } \\
\text { fruits G } \\
(\%)\end{array}$} & \multirow{2}{*}{$\begin{array}{c}\text { Total } \\
\text { B.E.R. } \\
\text { fruits G } \\
(\%)\end{array}$} & \multicolumn{4}{|c|}{ B.E.R. } & \multirow{2}{*}{$\begin{array}{c}\text { Number of } \\
\text { leaves below } \\
\text { 1st inflores- } \\
\text { cence }\end{array}$} \\
\hline & & $\begin{array}{l}\text { Mean total } \\
\text { fruit weight } \\
\text { (g) }\end{array}$ & $\begin{array}{l}\text { Mean number } \\
\text { of fruits }\end{array}$ & & & $\begin{array}{c}S \\
(\%)\end{array}$ & $\begin{array}{l}-25 \% \\
(\%)\end{array}$ & $\begin{array}{c}+25 \% \\
(\%)\end{array}$ & $\begin{array}{c}+50 \% \\
(\%)\end{array}$ & \\
\hline \multirow[t]{4}{*}{ Oct. 61} & $3 \mathbf{H}$ & 302 & 5,5 & 61 & 39 & 6 & 27 & 6 & 一 & 8 \\
\hline & H & 283 & 5,5 & 94 & 6 & 6 & - & - & - & 8 \\
\hline & $3 \mathrm{~L}$ & 237 & 5,0 & 100 & - & - & - & - & - & 8 \\
\hline & $\mathbf{L}$ & 246 & 5,0 & 100 & - & - & - & - & - & 8 \\
\hline \multirow[t]{4}{*}{ Nov. 61} & $3 \mathbf{H}$ & 276 & 6,0 & 46 & 54 & 3 & 10 & 38 & 3 & 10 \\
\hline & H & 250 & 6,0 & 52 & 48 & 6 & 18 & 24 & - & 10 \\
\hline & $3 \mathrm{~L}$ & 208 & 5,0 & 100 & - & - & - & - & - & 10 \\
\hline & L & 190 & 4,0 & 100 & - & - & - & - & - & 10 \\
\hline \multirow{4}{*}{ Dec. 61} & $3 \mathbf{H}$ & 232 & 5,0 & 52 & 48 & 28 & 12 & 8 & - & 9 \\
\hline & H & 237 & 5,0 & 88 & 12 & 8 & 4 & - & - & 9 \\
\hline & $3 \mathrm{~L}$ & 170 & 4,0 & 100 & - & - & - & - & - & 9 \\
\hline & $\mathbf{L}$ & 156 & 4,0 & 100 & - & - & - & - & - & 9 \\
\hline \multirow[t]{4}{*}{ Jan. 61} & $3 \mathbf{H}$ & 279 & 5,5 & 60 & 40 & 5 & 29 & 6 & - & 9 \\
\hline & $\mathbf{H}$ & 240 & 5,0 & 82 & 18 & 8 & 10 & - & - & 9 \\
\hline & $3 \mathrm{~L}$ & 212 & 5,0 & 100 & - & - & - & - & - & 9 \\
\hline & L & 188 & 5,0 & 100 & - & - & - & - & - & 9 \\
\hline
\end{tabular}

2-3 leaves were involved showing symptoms of various degrees from only signs to severe necrosis, relative to the vigour of the plant. During later stages of plant development again normal leaves were produced.

A pronounced reduction in leaf-area increase occurred from the time the first fruits were set for the high soil-moisture treatments; growth in height was not influenced. For the low soilmoisture treatments the production of leaf area was more regular.

Vigorous plants as a result of high soil moisture nearly always produced a number of affected fruits, while the less vigorously growing plants of the low soil-moisture treatments yielded only normal fruits. The vigorously growing plants were more susceptible to attacks by Cladosporium and Septoria fungi and a not identified virus resulting in reduced yields of the higher clusters.

Prevalence and severity of blossom-end rot. The number of affected fruits in the first cluster of plants growing under high soil moisture varied from $6-60 \%$ relative to time of planting and nitrogen fertilizer; low soil moisture prevented the incidence fully (table 2). The severity of the disorder ( $\mathrm{L} / \mathrm{F}$ ranging from 5-55\%) was most pronounced in the November planting when aiso the highest percentage of affected fruits occured.

Under the prevailing conditions the disorder was mainly confined to fruits of the first cluster except for the November plantings wherein also fruits of the second cluster were affected, but to a low percentage, and the L/F-ratio did not exceed $20 \%$. The third and fourth cluster were always free from the disorder. It is interesting to mention that this is in contrast to glasshouse tomatoes in Holland where blossom-end rot is most common in the higher clusters (GROENEWEGEN, 1957).

The percentage of blossom-end rot fruits in the first cluster varies with the vigour of the plant and there is a marked difference in severity of the disorder between affected fruits of the same cluster. In the November planting the third and fourth fruit of the first cluster showed the highest incidence percentage and also the greatest L/F-ratio. In all other plantings the fifth fruits most often were affected by the disorder.

There was a positive correlation between the number of affected fruits per cluster and the mean 
size of the lesion. When the number of affected fruits was small the maximum incidence occurred at the end of the cluster (youngest fruits); with increasing disorder the maximum moved towards the base of the cluster (older fruits).

Relation of blossom-end rot to age, size and development of the fruit. The incipient stages of the disorder for each fruit were found to occur from 7 to 10 days after anthesis. At this age the diameter of the fruit varied from $15-21 \mathrm{~mm}$ and was about $30-50 \%$ of its full grown size, dependent on the arrangement of the fruit on the cluster (table 3). In fruits produced near the end of the cluster the occurrence of the incipient stage was retarded and the diameter of the fruit at this age was smaller than that of earlier developed fruits.

TABLE 3. Incipient stages of blossom-end rot and diameter of fruits at this age for all plantings

\begin{tabular}{ccc}
\hline $\begin{array}{c}\text { Fruit number } \\
\text { on 1st cluster }\end{array}$ & $\begin{array}{c}\text { Mean age at incipient } \\
\text { stage after anthesis } \\
\text { (days) }\end{array}$ & $\begin{array}{c}\text { Mean diameter } \\
\text { of fruit } \\
\text { (mm) }\end{array}$ \\
1 & 8 & \\
2 & 8 & 19,2 \\
3 & 8 & 18,6 \\
4 & 8 & 18,3 \\
5 & 9 & 18,0 \\
6 & 10 & 16,3 \\
& & 15,6
\end{tabular}

The growth rate of fruits on low soil-moisture plants on which only normal fruits were produced was lower than that of normal and affected fruits on plants grown under high soil moisture. Comparing the growth rate of blossom-end rot fruits with that of normal fruits of the high soil-moisture treatments, the highest growth rate was found in fruits in which during the susceptible period the disorder developed (table 4).

TABLE 4. Development of normal and blossom-end rot fruits under different water regimes. Mean of the first three fruits of the first cluster for all plantings

\begin{tabular}{lcccccccc}
\hline \multicolumn{1}{c}{ Treatment } & \multicolumn{8}{c}{ Diameter of fruit at successive days after anthesis (mm) } \\
\cline { 2 - 8 } & 4 & 5 & 6 & 7 & 8 & 9 & 10 & 11 days \\
High moisture & & & & & & & & \\
B.E.R. fruits . . & 5,5 & 8,6 & 12,2 & 15,4 & 18,5 & 21,0 & 23,3 & 25,0 \\
High moisture & 4,8 & 7,1 & 10,2 & 13,3 & 16,1 & 19,1 & 21,9 & 24,3 \\
normal fruits .. & 4,8 & 6,1 & 8,5 & 11,3 & 13,9 & 16,3 & 18,8 & 21,0 \\
Low moisture . & 4,2 & &
\end{tabular}

Actual diameter and age at incipient stage of individual fruits may vary from these figures, since they are based on means.

Growth rate of fruits of the different plantings was highest for the November planting where the prevalence and severity of blossom-end rot was most pronounced (table 5).

The growth rate was also affected by the nitrogen-fertilizer application and so was the incidence of blossom-end rot (tables 2 and 6).

An analysis of the fruit growth during the susceptible period in a day and a night component indicated that both components are equal for the low soil-moisture treatments, but the night component was greater for the high soil-moisture treatments (table 7).

The diameter growth of affected fruits was only slightly depressed during the development period after the incidence. At maturity the diameter of these fruits did not differ much from the diameter of corresponding normal fruits. The height of the fruits was however reduced in relation to the size of the lesion and so was the fruit weight (table 8). 
Table 5. Development of fruits under high soil moisture for different times of planting. Mean of the first three fruits of the first cluster

\begin{tabular}{|c|c|c|c|c|c|c|c|c|}
\hline \multirow{2}{*}{$\begin{array}{l}\text { Time of } \\
\text { planting }\end{array}$} & \multicolumn{8}{|c|}{ Diameter of fruit at successive days after anthesis (mm) } \\
\hline & 4 & 5 & 6 & 7 & 8 & 9 & 10 & 11 days \\
\hline October & 4,6 & 7,0 & 9,8 & 13,9 & 16,0 & 18,8 & 21,4 & 23,8 \\
\hline November $\ldots$. & 5,4 & 8,2 & 11,4 & 14,8 & 18,0 & 20,6 & 22,8 & 24,6 \\
\hline December & 4,8 & 7,6 & 10,8 & 14,1 & 17,3 & 20,0 & 22,5 & 24,4 \\
\hline January & 5,0 & 7,9 & 11,2 & 14,5 & 17,6 & 20,2 & 22,6 & 24,4 \\
\hline
\end{tabular}

TABLE 6. Development of fruits under high soil moisture as affected by nitrogen fertilizer application. Mean of first three fruits of the first cluster for all plantings

\begin{tabular}{|c|c|c|c|c|c|c|c|c|}
\hline \multirow[t]{2}{*}{ Treatment } & \multicolumn{8}{|c|}{ Diameter of fruit at successive days after anthesis $(\mathrm{mm})$} \\
\hline & 4 & 5 & 6 & 7 & 8 & 9 & 10 & 11 days \\
\hline $3 \mathbf{H}$ & 5,4 & 8,1 & 11,5 & 14,6 & 17,6 & 20,6 & 22,8 & 27,4 \\
\hline$\ldots \ldots \ldots$ & 5,0 & 7,8 & 10,3 & 13,7 & 17,1 & 20,0 & 22,2 & 24,3 \\
\hline
\end{tabular}

TABLE 7. Analysis of fruit growth in day and night component for different water regimes. Mean increase over a six day period during highest susceptibility

\begin{tabular}{cccc}
\hline Treatment & $\begin{array}{c}\text { Total daily } \\
\text { increase }(\mathrm{mm})\end{array}$ & $\begin{array}{c}\text { Night component } \\
(\mathrm{mm})\end{array}$ & $\begin{array}{c}\text { Day component } \\
(\mathrm{mm})\end{array}$ \\
Low moisture & 2,4 & 1,2 & 1,2 \\
High moisture & 2,8 & 1,5 & 1,3 \\
\hline
\end{tabular}

TABLE 8. The effect of the severity of blossom-end rot on height and weight of the fruit

\begin{tabular}{ccc}
\hline $\begin{array}{c}\text { Severity of B.E.R. } \\
\text { L/F-ratio (\%) }\end{array}$ & $\begin{array}{c}\text { Height/diameter } \\
\text { ratio of fruit }\end{array}$ & $\begin{array}{c}\text { Fruit weight } \\
\text { reduction (\%) }\end{array}$ \\
$0-15$ & $0,90: 1$ & nil \\
$16-20$ & $0,85: 1$ & 2,0 \\
$21-25$ & $0,77: 1$ & 4,2 \\
$26-30$ & $0,70: 1$ & 7,6 \\
$31-35$ & $0,66: 1$ & 11,8 \\
$36-40$ & $0,62: 1$ & 15,1 \\
$41-45$ & $0,59: 1$ & 21,8 \\
$46-50$ & $0,56: 1$ & 26,3 \\
$51-55$ & $0,54: 1$ & 33,3 \\
\hline
\end{tabular}

Results of the additional treatments. An increase of the incidence of blossom-end rot resulted when plants were topped after appearance of the second inflorescence, when they were allowed to wilt after fruit setting and when the first inflorescence was removed, the standard high soilmoisture treatment $3 \mathrm{H}$ being taken as comparison.

The incipient stage for topped plants occurred at 9 days after anthesis when the mean diameter of the first three fruits was $21 \mathrm{~mm}$. The L/F-ratio differed only slightly from the $3 \mathrm{H}$-treatment. The disorder was more accentuated in wilted plants — incipient stage 8 days - and very pronounced in fruits of the second cluster of plants from which the first inflorescence was 
removed. In the latter treatment the incipient stage occurred at 7 days after anthesis and the L/F-ratio exceeded $50 \%$ in many fruits; also fruits of the third cluster were affected. Growth rates of fruits of all above mentioned treatments were higher than for the $3 H$-treatment, and highest for the inflorescence-removal plants.

A reduction of the disorder was obtained in the shade, leaf-removal, and multiple-stem treatments. Fruits of the first cluster of the multiple-stem treatment were even free of blossom-end rot but a slight incidence appeared in fruits of the second cluster, the L/F-ratio being always below $25 \%$. The growth rates of fruits of these treatments were always lower than that of the $3 \mathrm{H}-$ treatment and specially low for fruits on the first cluster of multiple-stem plants (table 9).

TABLE 9. Growth rates of fruits of additional treatments. Mean of the first three fruits of December and January plantings. Incipient stage in italics

\begin{tabular}{|c|c|c|c|c|c|c|c|c|}
\hline \multirow[t]{2}{*}{ Treatments } & \multicolumn{8}{|c|}{ Diameter of fruit at successive days after anthesis (mm) } \\
\hline & 4 & 5 & 6 & 7 & 8 & 9 & 10 & 11 days \\
\hline Standard $3 \mathbf{H}$ & 5,2 & 7,9 & 11,2 & 14,3 & 17,3 & 20,2 & 22,6 & 24,4 \\
\hline Leaf-removal. & 4,5 & 6,5 & 9,2 & 12,2 & 15,2 & 18,6 & 21,1 & 23,5 \\
\hline Shade $\quad \ldots \ldots \ldots$ & 4,4 & 6,0 & 9,3 & 12,2 & 15,2 & 18,8 & 21,5 & 23,8 \\
\hline Multiple-stem, & & & & & & & & \\
\hline 1 st inflorescence & 3,3 & 4,9 & 6,3 & 9,0 & 11,7 & 14,6 & 17,4 & 20,1 \\
\hline Multiple-stem, & & & & & & & & \\
\hline 2nd inflorescence & 4,0 & 6,2 & 9,5 & 12,5 & 16,0 & 18,7 & 20,7 & 22,3 \\
\hline Wilting $\ldots \ldots \ldots \ldots$ & 6,0 & 9,2 & 12,3 & 15,7 & 19,0 & 22,0 & 24,2 & 26,0 \\
\hline Topping & 5,6 & 9,0 & 11,8 & 15,2 & 18,5 & 21,1 & 24,0 & 26,0 \\
\hline Removal 1 inflorescence & 5,8 & 8,6 & 12,2 & 15,8 & 18,9 & 21,5 & 24,6 & 26,6 \\
\hline
\end{tabular}

\section{Discussion}

It was evident from the observational experiments that the growth vigour of the tomato plant influenced the occurrence of blossom-end rot of the fruits. Vigorous growth before anthesis of the first flower was responsible for the incidence of the disorder.

An analysis of plant development disclosed that high soil moisture from transplanting onwards induced rapid and vigorous growth until appearance of the first small fruits. At this stage leaf-area production decreased and symptoms of calcium deficiency appeared in the terminal bud. Only a few leaves were affected and leaves produced later were normal again. This implies that there must be a period during which the plant is very sensitive to calcium deficiency.

It was during this period that the incidence of blossom-end rot appeared in the fruit which can be considered to be near the extremities of the plant where calcium deficiency symptoms occur initially. The severity of the disorder was related to the degree of calcium deficiency in the leaves.

Our observations seemed to confirm SPURR's (1959) theory that calcium deficiency is the basic cause of blossom-end rot. Another indication was obtained from the fact that fruits on the higher clusters did not produce the disorder, even when the plant was allowed to wilt; but at this stage the plant showed no symptoms of calcium deficiency.

The occurrence of calcium deficiency during the sensitive period could be explained by assuming that the water-uptake is not in equilibrium with the water-requirement for vigorous growth resulting in a high water stress within the plant that in its turn is responsible for an inadequate calcium transport. Increased calcium content of the 
soil or an abundant water-supply could not prevent the disorder. This indicates that the deficiencies within the plant could not be controlled probably because the plant growth was out of balance.

The results obtained in the observational experiments suggested to study the effect of the vigour of the plant on blossom-end rot more in details. Two important factors, soil moisture and nitrogen nutrition, controlling the vigour of the plant were selected as main treatments in an experiment to obtain more information about the incidence of the disorder.

Control of soil moisture is a very effective means of influencing the growth rate of a plant. RAHMAN and Bierhuizen (1959) found in their tomato experiments that different water regimes (addition of water to bring soil to field capacity when $20 \%$ of the total moisture available in the soil was consumed (A) and when $95 \%$ was used (B)) had a great effect on the height and the evapotranspiration of tomato plants grown at $26^{\circ} \mathrm{C}$. For the $\mathrm{A}$ and B-treatments the height was $21,0 \mathrm{~cm}$ and $13,6 \mathrm{~cm}$ respectively and the evapotranspiration $4,30 \mathrm{~mm}$ and $1,06 \mathrm{~mm}$ per day. Nitrogen nutrition was selected as second factor because it does not only influence the growth rate of the plant but also produces larger and thinner leaves, both factors controlling transpiration.

The results of the replicated experiment confirmed those already obtained in the observational experiments. Only plants grown at high soil-moisture levels and showing calcium deficiency on the terminal bud produced blossom-end rot fruits on the first cluster. Nitrogen applications seemed to extend the sensitive calcium deficiency period for it happened that also fruits of the second cluster were affected in these treatments. The prolongation of the sensitive period may be caused by higher transpiration.

Analysis of fruits of the first cluster in relation to blossom-end rot incidence indicated that only a certain percentage of the fruits were affected and to various degrees of severity. Two reasons are considered to explain why all fruits were affected when plants showed even severe symptoms of calcium deficiency; firstly the fruits have passed the stage of development at which the incidence occurs before or after the calcium-deficiency sensitive period of the plant. Initial symptoms of blossom-end rot do not occur in advanced stages of growth, suggested to be due to a considerable increase of calcium content in the fruit after the susceptible period. Secondly the growth rate of the fruit is such that an adequate calcium supply can be still maintained for normal fruit production.

Calcium deficiency appears earlier in the terminal bud than in the fruit (SPURR, 1959) and only very small variations in calcium supply are sufficient to cause or prevent the disorder. This indicates why the incidence can be avoided only by a slight reduction in fruit growth (TABLE 4).

The severity of the disorder (L/F-ratio) and the percentage of affected fruits seemed to be dependent on the degree of calcium deficiency in the plant and the growth rate of the fruit.

The absence of blossom-end rot in fruits of plants grown at low soil-moisture levels may be attributed to a lower degree of calcium deficiency in the plant caused by reduction of leaf area and transpiration (RAHMAN and BIERHUIZEN, 1959) and to a reduction of fruit growth rate (TABLE 4).

Another factor which must not be overlooked is the evenly distributed growth rate of fruits of low soil-moisture plants during day and night (TABLE 7) that may be responsible for a constant and adequate calcium supply to the fruit, while the calcium supply to fruits of high soil-moisture plants might be depressed at day time. 
This hypothesis is based on the fact that, although nearly all fruits of the low soilmoisture treatments showed a low growth rate, some plants produced normal fruits having a growth rate similar to blossom-end rot affected fruits of the high soilmoisture treatments.

The difference in the percentage of affected fruits and the severity of the disorder for time of transplanting (TABLE 2) may be partly attributed to climatical conditions, but also to variations in the growth rate of fruits that seemed to be controlled by the number of leaves produced at the appearance of the first inflorescence. The assimilation process is directly related to the leaf area and the quantity of assimilates produced will influence the growth rate of the fruit. The October planting, when only 8 leaves were present (TABLE 2) at appearance of the first inflorescence, showed the lowest percentage of blossom-end rot.

Larger leaf-area production and higher transpiration of the nitrogen-treatment plants are supposed to be responsible by increasing the calcium deficiency in the plant and the growth rate of the fruit for a greater incidence of rot than present in the nilnitrogen treatments.

The additional treatments confirm that the incidence of blossom-end rot depends not only on calcium deficiency in the plant but also on the growth rate of the fruit.

Removal of the first inflorescence resulted in an increased growth rate of fruits of the second cluster, a larger leaf area being available for assimilation (TABLE 9) for the production of these fruits. This suggests why fruits of this treatment were so heavily affected. By removal of leaves below the first inflorescence it was possible to reduce the fruit-growth rate by reduction of the assimilating surface.

Although severe calcium-deficiency symptoms appeared in plants of this treatment there was a considerable reduction in the prevalence and severity of the disorder. It is likely that this can be attributed to the depressed growth rate of the fruit.

Topping after appearance of the second inflorescence gave a relatively small increase in fruit growth. Only part of the nutrients otherwise used for new leaf production was directed to the fruits, the other part contributed to the vigorous development of the top leaves. The increase in growth rate and, at the same time, a slight improvement of the calcium supply to the fruits seemed to be responsible for the retarded occurrence of the disorder and for a reduction of the severity (TABLE 9).

Allowing the plants to wilt during the blossom-end rot susceptible period will definitely affect the calcium transport within the plant. More severe symptoms of the disorder in the wilting treatment can probably be explained in this way. The growth rate of these fruits was hardly affected (TABLE 9).

In multiple-stem plants calcium-deficiency symptoms appeared at a later stage of plant development than in single-stem plants. Root-system studies might give an answer to this fact supposing that the adequate calcium supply could be maintained for a longer time in multiple-stem plants due to a more extensive root system.

All fruits of the first cluster were free of blossom-end rot. The growth rate of these fruits was considerably reduced, nutrients and water being shared between the different stems. The reduction of fruit growth on itself should already prevent the incidence of blossom-end rot apart from the fact that the calcium deficiency is less severe.

The growth rate of fruits on the second cluster was more vigorous (TABLE 9) and this, together with the later appearance of calcium deficiency in the plant, might give an answer for the occurrence of the disorder in some of these fruits. 


\section{Conclusion}

Calcium deficiency in the fruit seems to be the basic cause of blossom-end rot in tomatoes. Even when the soil solution contains an adequate calcium content, calciumdeficiency symptoms may appear in the plant due to a series of factors as growth rate and lack of equilibrium between water uptake and transpiration. The calcium deficiency in the terminal bud has its influence on the availability of calcium to the fruit. It depends on the growth rate of the fruit whether under calcium-deficiency symptoms in the plant blossom-end rot will occur. At a relatively slow development of the fruit adequate calcium seems to be always available to produce normal fruits, but at a growth rate above a certain level the calcium deficiency will extend to the fruit itself and result in the disorder. An evenly distributed growth rate over the day and night period may also help to prevent calcium deficiency in the fruit.

\section{ACKNOWLEDGEMENTS}

I am indebted to Professor H. Nicol and Mr. F. Geurts for thoughtful reading of the manuscript and for their useful suggestions.

\section{I T E R A T U R E}

Abd El Rahman, A. A., and J. F. BIERHUIZEN

BAIN, D. C.

Geraldson, C. M.

GROENEWEGEN, J.

Gustafson, F. G., and Helen B. Houghtaling HÅRD, J. E.

Hulea, F.

Leopold, A. C., and Frances S. Guernsey MCIlRath, W. J.

Rieuf, P.

RobBins, W. R.

SPURR, A. R.

Stout, G. J.

Wallace, $T$.
1959 The effect of temperature and water supply on growth, transpiration and water requirements of tomato under controlled conditions. Meded. Landbouwh.school, Wageningen. 59, 3: $1-13$.

1954 Relation of staking and pruning to the incidence of blossomend rot of tomato. Plant Dis. Reptr. 38, 721-722.

1955 The use of calcium for control of blossom-end rot of tomatoes. Florida State Hort. Soc. Proc. 68, 197-202.

1957 Control of blossom-end rot of tomatoes. Amer. Soc. Hort. Sci. Proc. 69, 309-317.

1957 Neusrot bij tomaten. Groenten en Fruit. July.

1939 Relation between fruit size and food supply in tomatoes. Plant Physiol. 14, 321-332.

1957 Om topprötans fysiologiska bakgruns hos tomat. Nord. Jordbr. Forskn. 39, 432- 448 (English summary).

1958 Putregaiul inclar al tomatelor. Grad. Via. Liv. 7, 48-53. (English summary).

1953 The effect of nitrogen upon fruit abnormalities in the tomato. Amer. Soc. Hort. Sci. Proc. 61, 333-338.

1950 Growth reponses of tomato to nutrient ion adsorbed on a humic substrate. Plant Physiol. 25, 682-701.

1954 Au sujet du desèchement apical de la tomate. Terre Maroc. $28,89-90$.

1937 Relation of nutrient salt concentration to growth of the tomato and the incidence of blossom-end rot of the fruit. Plant Physiol. 12, 21-50.

1959 Anatomical aspects of blossom-end rot in the tomato with special reference to calcium nutrition. Hilgardia. 28, 269295.

1934 Influence of water treatment on the incidence of blossomend rot in greenhouse tomatoes. Amer. Soc. Hort. Sci. Proc. $32,525-528$.

1951 The diagnosis of mineral deficiencies. The London Stationary Office, Plates 252, 254. 